Research Article

\title{
The UCP2 -866G/A, Ala55Val and UCP3 -55C/T polymorphisms are associated with premature coronary artery disease and cardiovascular risk factors in Mexican population
}

\author{
Ricardo Gamboa ${ }^{1}$, Claudia Huesca-Gómez ${ }^{1}$, Vanessa López-Pérez ${ }^{1}$, Rosalinda Posadas-Sánchez ${ }^{2}$, Guillermo \\ Cardoso-Saldaña ${ }^{2}$, Aida Medina-Urrutia ${ }^{2}$, Juan Gabriel Juárez-Rojas ${ }^{2}$, María Elena Soto ${ }^{4}$, Carlos \\ Posadas-Romero ${ }^{2}$ and Gilberto Vargas-Alarcón ${ }^{3}$ \\ ${ }^{1}$ Department of Physiology, Instituto Nacional de Cardiología "Ignacio Chávez”, Mexico D.F., Mexico. \\ ${ }^{2}$ Department of Endocrinology, Instituto Nacional de Cardiología "Ignacio Chávez", Mexico D.F., Mexico. \\ ${ }^{3}$ Department of Molecular Biology, Instituto Nacional de Cardiología "Ignacio Chávez”, Mexico D.F., \\ Mexico. \\ ${ }^{4}$ Department of Immunology, Instituto Nacional de Cardiología “Ignacio Chávez”, Mexico D.F., Mexico.
}

\begin{abstract}
We examined the role of UCP gene polymorphisms as susceptibility markers for premature coronary artery disease (pCAD). The UCP2 Ala55Val (C/T rs660339), UCP2 -866G/A (rs659366), and UCP3 -55C/T (rs1800849) polymorphisms were genotyped in 948 patients with PCAD, and 763 controls. The distribution of the UCP2 A55V (C/T rs660339) and UCP3 -55 (rs1800849) was similar in patients and controls. However, under a recessive model, the UCP2 -866 (rs659366) $A$ allele was associated with increased risk of developing pCAD (OR $=1.43, P C=0.003)$. On the other hand, patients with $\mathrm{pCAD}$ and UCP2 A55V (rs660339) TT showed high levels of visceral abdominal fat (VAF) $(P C=0.002)$, low levels of subcutaneous abdominal fat $(\mathrm{SAF})(P C=0.001)$ and high VAT/SAT ratio $(P C<$ 0.001). Also, patients with UCP2 -866 (rs659366) $A A$ showed increased levels of VAF $(P C=0.003)$, low levels of SAF $(P C=0.001)$ and a high VAT/SAT ratio $(P C=0.002)$, whereas patients with the UCP3 -55 (rs1800849) TT presented high levels of $\operatorname{VAF}(P C=0.002)$. The results suggest the association of the UCP2 -866 (rs659366) polymorphism with risk of developing $\mathrm{PCAD}$. Some polymorphisms were associated with abdominal fat levels and cardiovascular risk factors.
\end{abstract}

Keywords: UCPs polymorphisms, premature coronary artery, cardiovascular risk, Mexican population.

Received: January 10, 2017; Accepted: October 18, 2017.

\section{Introduction}

The incidence and prevalence of coronary artery disease (CAD) has been increasing in recent decades, becoming one of the leading causes of mortality worldwide. It is known that obesity is one of the main factors associated with CAD (Makedou et al., 2009; Pischon et al., 2009; Center for Disease Control and Prevention, 2010). Adipose tissue, in particular the intra-abdominal visceral fat, is able to synthesize and release a variety of hormones and cytokines, which are active molecules relevant in the development of CAD. Furthermore, excess adipose tissue is associated with factors that increase the risk of developing CAD such as hyperinsulinemia, insulin resistance, hypertension, and dyslipidemia (Kil et al., 2005; Muzzio et al., 2005). There is evidence suggesting that obesity is associ-

Send correspondence to Gilberto Vargas-Alarcón, Instituto Nacional de Cardiología "Ignacio Chávez" Juan Badiano No 1, Col. Sección XVI, 14080 Mexico, D.F., Mexico.E-mail: gvargas63@yahoo.com. ated with cardiac hemodynamics. So, obesity is linked to hyperdynamic circulation, which maintains the metabolic demand caused by excessive fat deposition. Several studies have shown a positive association between body weight and CAD (Vasan, 2003; Zamboni et al., 2005). Moreover, energy expenditure is a complex trait comprised of the resting metabolic rate, the energy expenditure due to physical activity and diet-induced adaptive thermogenesis. In this context, uncoupling proteins (UCPs) are a family of mitochondrial transporters, which play a crucial role in the process of adaptive thermogenesis (Gronek and Holdys, 2013). UCP function is primarily the uncoupling of the mitochondrial oxidative phosphorylation by promoting the leakage of protons across the inner mitochondrial membrane without their passing through the charge path to synthesize ATP (a process involved in the production of heat). As a result of this decoupling mechanism, a mobilization of stored triglycerides ensues, which plays an important role in fat metabolism. 
UCPs are integral proteins located in the mitochondrial inner membrane; they have a molecular mass ranging from $31 \mathrm{kDa}$ to $34 \mathrm{kDa}$ (Ledesma et al., 2002). The uncoupling protein UCP-2 is widely expressed in various human tissues, such as the spleen, thymus, leukocytes, macrophages, bone marrow and stomach (Boss et al., 1997; Fleury et al., 1997). In this regard, $U C P-2$ mRNA levels in these tissues and in intra-abdominal subcutaneous adipose tissue are lower in obese subjects compared to lean subjects. On the other hand, several studies have already described that UCP-2 has an anti-atherogenic effect in the vascular wall (Blanc et al., 2003), it improves tolerance to cardiac ischemia (McLeod et al., 2005; Cheurfa et al., 2008) and protects cardiomyocytes from oxidative stress induced cell death (Teshima et al., 2003). In contrast, the uncoupling protein UCP-3 is highly specific of the skeletal muscle, and it has been suggested that it is one of the main regulators of adaptive thermogenesis in humans (Argiles et al., 2002; Schrauwen et al., 2002). Some studies have reported associations between uncoupling protein UCP's polymorphisms and type 2 diabetes mellitus (T2DM). Particular attention has been focused on the UCP-1 $-3826 \mathrm{~A} / \mathrm{G}$ (rs1800592), UCP2 -866G/A (rs659366), UCP2 Ala55Val $(C / T$; rs660339) and $U C P 3-55 C / T$ (rs1800849) polymorphisms. However, the results of these studies are controversial with positive and negative associations (Jia et al., 2009, Jia et al., 2010; De Souza et al., 2011; Brondani et al., 2012). This point is of great relevance since it has been observed that almost $70 \%$ of patients with diabetes or impaired glucose tolerance present cardiovascular disease (Norhammar et al., 2002). Also, some studies have shown that polymorphisms of the UCP genes may contribute to metabolic disorders with major effects on energy metabolism. The polymorphism -866 G/A (rs659366) has been significantly associated with asymptomatic carotid artery atherosclerosis in women (Oberkofler et al., 2005) and with CAD in men (Dhamrait et al., 2004). It is known that acute coronary syndromes are the result of a progressive transformation of fatty streaks in atherosclerotic plaques. In these patients, surgery has proven to be a treatment option, which improves symptoms, quality of life and prognosis. In this context, it is important to study the role of UCPs, given that these uncoupling proteins are actively involved in the storage of fat, which constitutes a major cardiovascular risk factor. Therefore, the identification of variants in the $U C P$ genes (UCP2 -866, UCP2 A55V and UCP3 -55C/T) in patients with CAD will aid in evaluating their participation in the predisposition to this disease.

\section{Subjects and Methods}

\section{Subjects and measures}

All participants gave written informed consent. The study complied with the Declaration of Helsinki and was approved by the Ethics Committee of the Instituto Nacional de Cardiología Ignacio Chávez (INCICh). The primary aim of the Genetics of Atherosclerotic Disease (GEA) Study is to investigate genetic factors associated with pCAD, subclinical atherosclerosis (SA) and other coronary risk factors in the Mexican population. All GEA participants are unrelated and of self-reported Mexican-mestizo ancestry (for at least three generations). Incidentally, a Mexican-mestizo is defined as someone born in Mexico who is a descendant of both the original autochthonous inhabitants and Caucasian (predominantly Spaniards) and/or African individuals. We analyzed 1711 individuals, 948 diagnosed with pCAD and 763 healthy unrelated controls (with negative calcium score by computed tomography). pCAD was defined by personal history of myocardial infarction, angioplasty, bypass surgery, or coronary stenosis $>50 \%$ (determined by angiography). Selection was performed among the out-patients and patients attending for diagnostic or therapeutic catheterization. Only patients with pCAD (age at diagnosis $<55$ years in men and $<65$ in women) who did not experience acute cardiovascular events in the three months prior to the study were included. Also, patients with congestive heart failure, liver disease, kidney cancer, untreated dysthyroidism and those with corticosteroid treatment were not included. Controls were apparently healthy asymptomatic individuals without family history of pCAD; they were recruited from blood bank donors and through brochures posted at social service centers. Exclusion criteria for controls included congestive heart failure, liver, renal, thyroid or oncological disease. The selection of the patients and controls for the GEA study was described in a previous study (Villarreal-Molina et al., 2012). All participants filled out standardized questionnaires to provide demographic information, level of education, income, family and personal history of cardiovascular disease, dietary habits, physical activity, alcohol consumption and use of drugs and supplements.

Blood samples were obtained from subjects after a $12-\mathrm{h}$ fasting period. Next, they were centrifuged to separate serum samples. Serum biochemical profiles [total cholesterol, triglycerides, high-density lipoprotein-Cholesterol (HDL-C), apolipoprotein A (Apo A), apolipoprotein B (Apo B) and glucose] were measured with standardized enzymatic procedures using a Hitachi 902 auto-analyzer (Hitachi Ltd., Tokyo, Japan). LDL-C was estimated using the De Long et al. (1986) formula. Accuracy and precision of lipid measurements in our laboratory are under periodic surveillance by the Centers for Disease Control and Prevention service (Atlanta, GA, USA). Uric acid, insulin, alanine aminotransferase (ALT), aspartate aminotransferase (AST), alkaline phosphatase (ALP), and creatinine were measured as well. Plasma insulin concentrations were determined by a RIA (Millipore; RIA Kit, Cat. No. HI-14K, $\mathrm{MO}, \mathrm{USA})$, the intra- and interassay CV values were 2.1 and $6.8 \%$, respectively. The homeostasis assessment model of insulin resistance (HOMA-IR) was calculated using the 
formula: [fasting insulin (pmol/L) x times / fasting glucose $(\mathrm{mmol} / \mathrm{L})] / 135$. Samples for each human subject were analyzed as a single batch. Specifically, the interassay coefficient of variation for the assays was less than $5 \%$.

\section{Computed tomography of the chest and abdomen}

Computed tomography of the chest and abdomen were performed using a 64-channel multi-detector helical computed tomography system (Somatom Sensation, Siemens) and interpreted by experienced radiologists. Scans were read to assess and quantify three parameters: 1) Coronary artery calcification (CAC) score using the Agatston method (Mautner et al., 1994); 2) total abdominal fat (TAF), subcutaneous abdominal fat (SAF) and visceral abdominal fat (VAF) as described by Kvist et al. (1988), in order to estimate visceral to subcutaneous adipose tissue ratio (VAT/SAT); and 3) hepatic to splenic attenuation ratio (LSAR) as described by Longo et al. (1993). All patients and a group of 950 healthy controls underwent a tomography examination. Remarkably, 187 subjects in the apparently healthy control group presented positive CAC (CAC score $>0$ ) and were considered as individuals with subclinical atherosclerosis. These subjects were not considered in the analysis. The control group only included individuals with negative CAC $(\mathrm{n}=763)$.

\section{DNA preparation}

Genomic DNA was extracted from whole blood containing EDTA by standard techniques. The UCP2 Ala55 Val (C/T rs660339), UCP2 -866G/A (rs659366), and UCP3 -55C/T (rs1800849) polymorphisms were genotyped using 5' exonuclease TaqMan genotyping assays on an ABI Prism 7900HT Fast Real-Time PCR system, according to manufacturer's instructions (Applied Biosystems, Foster City, CA, USA)

\section{Statistical analysis}

All calculations were performed using SPSS version 18.0 (SPSS, Chicago, Il, USA) statistical package. Means \pm SD and frequencies of baseline characteristics were estimated. Chi-square test was used to compare frequencies and ANOVA and Student's $t$-test was used to compare means. Variables with skewed distribution were shown as median (minimum-maximum) and analyzed using a nonparametric test. Logistic regression analysis was used to test for polymorphism associations with pCAD under inheritance models, adjusted by age, gender, body mass index (BMI), and HDL-C levels. ANCOVA was used to determine associations between the polymorphisms and some clinical and metabolic variables, adjusting for the significant confounding factors like age, gender, smoking habit and physical activity as appropriate. Bonferroni correction was employed to control for multiple testing. The $p$-values for associations of the polymorphisms with pCAD were corrected by three comparisons, for associations with sub- cutaneous, visceral and total fat were corrected by four comparisons and for associations with cardiovascular risk factors were corrected by seven comparisons. The corrected $\mathrm{p}$ values are indicated as $P c$. Genotype frequencies did not show deviation from Hardy-Weinberg equilibrium (HWE) $(P>0.05)$. Pairwise linkage disequilibrium (LD, D') estimations between polymorphisms and haplotype reconstruction were performed with Haploview version 4:1 (Broad Institute of Massachusetts Institute of Technology and Harvard University, Cambridge, MA, USA).

\section{Results}

General clinical characteristics of the population are shown in Tables 1 and 2. The statistical differences between groups are shown.

Observed and expected frequencies in the studied polymorphisms were in HWE. The distribution of the UCP2 A55V (rs660339) and UCP3 -55 (rs1800849) polymorphisms was similar in patients with pCAD and healthy controls in all the models analyzed (Table 3 ). However, under the recessive model adjusted for age, gender, BMI, and HDL-C, the UCP2 -866 (rs659366) polymorphism was associated with an increased risk of developing pCAD $(\mathrm{OR}=$ $1.43,95 \% \mathrm{CI}: 1.15-1.78, P c=0.003)$. Statistical power to detect associations with UCP2 Ala55 Val (C/T rs660339), UCP3 -55C/T (rs1800849), and UCP2 $-866 \mathrm{G} / \mathrm{A}$ (rs659366) was $0.20,0.06$ and $>0.80$, respectively, as estimated with QUANTO software (biostats.usc.edu/Quanto.html).

The association of the polymorphisms with TAF, SAF and VAF was analyzed in pCAD patients (Table 4). In this analysis, patients with the UCP2 A55V (rs660339) TT genotype presented high levels of VAF $(P c=0.002)$, low levels of SAF $\left(P_{c}=0.001\right)$ and high VAT/SAT ratio $\left(P_{c}<\right.$ 0.001). Also, pCAD patients with the UCP2 -866 (rs659366) $A A$ genotype showed increased levels of VAF $(P c=0.003)$, low levels of SAF $(P c=0.001)$ and high $\mathrm{VAT} / \mathrm{SAT}$ ratio $\left(P_{c}=0.002\right)$, whereas $\mathrm{pCAD}$ patients with the UCP3 -55 (rs1800849) TT genotype showed high levels of $\operatorname{VAF}(P c=0.002)$.

The association of the $U C P$ polymorphisms with cardiovascular risk factors and metabolic parameters was analyzed (Table 5). The UCP2 A55V (rs660339) polymorphism was associated with $\mathrm{BMI}>30 \mathrm{~kg} / \mathrm{cm}^{2}(\mathrm{OR}=1.64$, 95\% CI: $1.30-2.06, P c_{\text {rec }}=0.003$; OR $=1.44,95 \% \mathrm{CI}$ : $\left.1.15-1.80, P c_{a d d}=0.001\right)$ and LDL-C $>130 \mathrm{mg} / \mathrm{dL}(\mathrm{OR}=$ 3.01, 95\% CI: 2.40-3.78, $\left.\mathrm{Pc}_{\mathrm{add}}=0.015\right)$. The UCP2 -866 (rs659366) was associated with BMI $>30 \mathrm{~kg} / \mathrm{cm}^{2}(\mathrm{OR}=$ $1.45,95 \%$ CI: $\left.1.16-1.81, P c_{a d d}=0.030\right)$, blood pressure $>$ $140 \mathrm{mmHg}\left(\mathrm{OR}=1.72,95 \% \mathrm{CI}: 1.23-2.41, P c_{a d d}=0.049\right)$, hypercholesterolemia $\left(\mathrm{OR}=3.41,95 \% \mathrm{CI}: 2.22-5.26, P c_{\text {rec }}\right.$ $\left.=0.006 ; \mathrm{OR}=1.65,95 \% \mathrm{CI}: 1.26-2.17, P c_{a d d}=0.038\right)$, and T2DM $\left(\mathrm{OR}=2.72,95 \% \mathrm{CI}: 1.64-4.50, P c_{\text {rec }}=0.001 ; \mathrm{OR}=\right.$ $2.85,95 \%$ CI: $\left.1.74-4.65, P c_{\text {add }}<0.001\right)$. Finally, the UCP3 $-55 C / T$ (rs1800849) polymorphism was associated with 
Table 1 - Demographic and clinical characteristics of the study population

\begin{tabular}{lccc}
\hline & Control group N=763 & pCAD group N=948 & \multicolumn{1}{c}{ ( } \\
\hline Sex W/M (\%) & $80.1 / 19.9$ & $19.1 / 80.9$ & 0.001 \\
Age (years) & $52.2 \pm 8.9$ & $53.5 \pm 7.8$ & 0.002 \\
Body Mass Index (kg/cm2) & $28.1 \pm 4.6$ & $28.5 \pm 4.1$ & 0.245 \\
Systolic Pressure (mmHg) & $114.5 \pm 16.6$ & $118.2 \pm 18.2$ & $<0.001$ \\
Diastolic Pressure (mmHg) & $70.7 \pm 8.9$ & $72.4 \pm 9.8$ & 0.001 \\
Overweight (\%) & 45.6 & 48.0 & $<0.001$ \\
Obesity $(\%)$ & 29.5 & 33.9 & $<0.001$ \\
Smoker $(\%)$ & 48.4 & 49.5 & $<0.001$ \\
HT $(\%)$ & 17.3 & 66.4 & $<0.001$ \\
Hepatic steatosis $(\%)$ & 29.7 & 26.8 & 0.289 \\
VAF/SAF $\left(\mathrm{cm}^{2}\right)$ & $0.554(014-3.21)$ & $0.721(0.14-4.52)$ & $<0.001$ \\
SAF $\left(\mathrm{cm}^{2}\right)$ & $304.94(64-713)$ & $260.22(57-774)$ & $<0.001$ \\
VAF $\left(\mathrm{cm}^{2}\right)$ & $147.89(27-473)$ & $172.60(23-504)$ & $<0.001$ \\
Total Abdominal Fat $\left(\mathrm{cm}^{2}\right)$ & $452.90(91-1032)$ & $432.44(113-1031)$ & 0.071 \\
\hline
\end{tabular}

Data are expressed as means $\pm \mathrm{SD}$, percentage or median (min-max).

HT: Hypertension, SAF: Subcutaneous abdominal fat, VAF: Visceral abdominal fat.

blood pressure $>140 \mathrm{mmHg}(\mathrm{OR}=6.53,95 \% \mathrm{CI}: 5.16-$ $8.27, P c_{\text {rec }}=0.007 ;$ OR $=6.55,95 \%$ CI: $5.21-8.31, P c_{\text {add }}=$ 0.011), hypercholesterolemia (OR $=2.53,95 \%$ CI: $1.92-$ $3.44, P c_{\text {rec }}=0.007 ; \mathrm{OR}=2.56,95 \%$ CI: $1.95-3.49, P c_{\text {add }}=$ $0.011)$, hypertriglyceridemia $(\mathrm{OR}=1.99,95 \% \mathrm{CI}: 1.61$ -

Table 2 - Metabolic characteristics of the study population

\begin{tabular}{lccc}
\hline & $\begin{array}{c}\text { Control group } \\
\mathrm{N}=763\end{array}$ & $\begin{array}{c}\text { pCAD group } \\
\mathrm{N}=948\end{array}$ & $P$ \\
\hline $\begin{array}{l}\text { Total-Cholesterol } \\
\text { (mg/dL) }\end{array}$ & $192.09 \pm 35.8$ & $165.83 \pm 46.92$ & $<0.001$ \\
HDL-C (mg/dL) & $50.06 \pm 14.39$ & $41.28 \pm 10.85$ & $<0.001$ \\
LDL-C (mg/dL) & $116.46 \pm 31.22$ & $96.31 \pm 38.92$ & $<0.001$ \\
TG (mg/dL) & $160.78 \pm 100.34$ & $175.83 \pm 101.32$ & 0.007 \\
Glucose (mg/dL) & $96.08 \pm 31.20$ & $103.06 \pm 34.74$ & $<0.001$ \\
Insulin (mg/dL) & $18.89 \pm 9.63$ & $23.06 \pm 14.97$ & $<0.001$ \\
HOMA-IR & $4.54 \pm 2.95$ & $5.82 \pm 4.68$ & $<0.001$ \\
Uric acid (mg/dL) & $5.10 \pm 1.31$ & $6.40 \pm 1.61$ & $<0.001$ \\
Creatinine (mg/dL) & $0.78 \pm 0.17$ & $1.00 \pm 0.17$ & $<0.001$ \\
ALT (IU/L) & $27.36 \pm 19.55$ & $29.8 \pm 19.97$ & 0.023 \\
AST (IU/L) & $27.35 \pm 12.62$ & $28.07 \pm 10.59$ & 0.606 \\
ALP (IU/L) & $84.59 \pm 25.95$ & $80.49 \pm 25.49$ & 0.005 \\
ApoB (mg/dL) & $92.01 \pm 27.00$ & $83.10 \pm 31.05$ & $<0.001$ \\
ApoA (mg/dL) & $143.03 \pm 34.39$ & $127.34 \pm 27.00$ & $<0.001$ \\
T2DM (\%) & 9.7 & 23.1 & $<0.001$ \\
\hline
\end{tabular}

Data are expressed as means \pm SD. HDL-C: High density lipoproteinCholesterol, LDL-C: Low density lipoprotein-Cholesterol, TG: Triglycerides, HOMA: Homeostatic model in insulin resistance, ALT: Alanine aminotransferase, AST: Aspartate aminotransferase, ALP: Alkaline phosphatase, T2DM: Type 2 Diabetes mellitus
2.53, $P c_{\text {rec }}=0.006 ;$ OR $=2.01,95 \%$ CI: $1.69-2.62, P c_{\text {add }}=$ $0.010)$, and T2DM $\left(\mathrm{OR}=2.26,95 \% \mathrm{CI}: 1.70-3.01, P c_{\text {rec }}=\right.$ $0.007 ; \mathrm{OR}=2.30,95 \%$ CI: $\left.1.74-3.06, P c_{a d d}=0.011\right)$.

The analysis of haplotypes showed one block composed of two polymorphisms in linkage disequilibrium $\left(D^{\prime}=0.964, r^{2}=0.881\right), U C P 2 A 55 V(r s 660339)$ and $U C P 2$ -866 (rs659366). The analyses showed three different possible allele combinations $(G C, A T$ and $A C$ ). Nonetheless, the distribution of these haplotypes was similar in both pCAD patients and healthy controls (data no shown).

\section{Discussion}

It is known that many molecular mechanisms are implicated in cardiovascular damage. These mechanisms include advanced glycation end products (AGE), protein kinase $\mathrm{C}$, polyol and hexosamine pathway. They appear to be associated with an overproduction of superoxide by the mitochondrial electron transport chain (Gioli-Pereira et al., 2013). In this phenomenon participate the uncoupling proteins (UCPs) and in consequence, the genes that encode these molecules (UCP1, UCP2 and UCP3) are regarded as candidate genes for obesity, T2DM and cardiovascular disease. Therefore, the identification of variants present in $U C P$ genes and their relation to visceral and subcutaneous adipose tissue and lipid parameters in patients with $\mathrm{CAD}$ can assist in evaluating their participation in predisposition to this disease. Previous studies have explored the effects of these genes on various traits in different populations (Holdys et al., 2013). However, results are inconsistent concerning the association with dyslipidemic parameters.

In the present study, we determined whether the UCP2 Ala55Val (rs660339), UCP2 -866G/A (rs659366), and $U C P 3-55 C / T$ (rs 1800849) polymorphisms are associ- 
Table 3 - Association of $U C P$ polymorphisms with pCAD.

\begin{tabular}{|c|c|c|c|c|c|c|c|}
\hline \multirow[b]{2}{*}{$U C P 2 A 55 V$} & \multicolumn{3}{|c|}{ N (\%) } & \multirow[t]{2}{*}{ MAF } & \multirow[t]{2}{*}{ Model } & \multirow[t]{2}{*}{ OR $(95 \% \mathrm{CI})$} & \multirow[t]{2}{*}{$P c$} \\
\hline & $C / C$ & $C / T$ & $T / T$ & & & & \\
\hline $\begin{array}{l}\text { Control } \\
(\mathrm{N}=763)\end{array}$ & $191(25.0)$ & $394(51.7)$ & $178(23.3)$ & 0.491 & Dominant & $0.095(0.76-1.19)$ & 0.682 \\
\hline pCAD & $256(27.1)$ & 459 (48.7) & $228(24.2)$ & 0.485 & Recessive & $1.15(0.92-1.43)$ & 0.193 \\
\hline$(\mathrm{N}=943)$ & & & & & Additive & $1.09(0.88-1.35)$ & 0.114 \\
\hline$U C P 2-866$ & $G / G$ & $G / A$ & $A / A$ & & & & \\
\hline $\begin{array}{l}\text { Control } \\
(\mathrm{N}=763)\end{array}$ & $222(29.1)$ & $377(49.4)$ & $164(21.5)$ & 0.461 & Dominant & $0.82(0.65-1.03)$ & 0.098 \\
\hline $\begin{array}{l}\text { pCAD } \\
(\mathrm{N}=943)\end{array}$ & $211(22.2)$ & $501(52.8)$ & $236(24.9)$ & 0.513 & $\begin{array}{c}\text { Recessive } \\
\text { Additive }\end{array}$ & $\begin{array}{l}1.43(1.15-1.78) \\
0.68(0.53-0.85)\end{array}$ & $\begin{array}{c}0.003 \\
<0.001 \\
\end{array}$ \\
\hline$U C P 3-55$ & $C / C$ & $C / T$ & $T / T$ & & & & \\
\hline $\begin{array}{l}\text { Control } \\
(\mathrm{N}=763)\end{array}$ & $552(72.3)$ & $192(25.2)$ & $19(2.5)$ & 0.150 & Dominant & $1.29(0.67-2.49)$ & 0.432 \\
\hline pCAD & $708(74.7)$ & $219(23.3)$ & $18(1.9)$ & 0.134 & Recessive & $1.14(0.91-1.41)$ & 0.229 \\
\hline$(\mathrm{N}=943)$ & & & & & Additive & $1.15(0.93-1.42)$ & 0.362 \\
\hline
\end{tabular}

pCAD: premature coronary artery disease. MAF: Minor Allele Frequency. The models were adjusted by age, gender, BMI, and HDL-C. Bonferroni correction was made multiplying by 3 comparisons $(P c)$. Significant $\mathrm{p}$ values are in bold.

Table 4 - Association of the $U C P$ polymorphisms with subcutaneous, visceral and total fat.

\begin{tabular}{|c|c|c|c|c|c|c|c|c|c|}
\hline & \multicolumn{3}{|c|}{ UCP2 $55 T T$} & \multicolumn{3}{|c|}{$U C P 2-866 A A$} & \multicolumn{3}{|c|}{ UCP3 -55 TT } \\
\hline & $\mathrm{pCAD}$ & Control & $P c$ & pCAD & Control & $P c$ & pCAD & Control & $P c$ \\
\hline VAT/SAT & $\begin{array}{c}0.682 \\
(0.14-2.25)\end{array}$ & $\begin{array}{c}0.547 \\
(0.15-2.54)\end{array}$ & $<0.001$ & $\begin{array}{c}0.703 \\
(0.14-2.11)\end{array}$ & $\begin{array}{c}0.545 \\
(0.14-3.21)\end{array}$ & 0.002 & $\begin{array}{c}0.696 \\
(0.14-4.52)\end{array}$ & $\begin{array}{c}0.561 \\
(0.14-3.21)\end{array}$ & 0.247 \\
\hline SAF & $\begin{array}{c}263.51 \\
(28-639)\end{array}$ & $\begin{array}{c}310.14 \\
(66-663)\end{array}$ & 0.001 & $\begin{array}{c}255.07 \\
(78-722)\end{array}$ & $\begin{array}{c}305.12 \\
(66-674)\end{array}$ & 0.001 & $\begin{array}{c}260.92 \\
(58-774)\end{array}$ & $\begin{array}{c}307.35 \\
(64-713)\end{array}$ & 0.524 \\
\hline VAF & $\begin{array}{c}172.66 \\
(35-445)\end{array}$ & $\begin{array}{c}149.80 \\
(41-464)\end{array}$ & 0.002 & $\begin{array}{c}175.49 \\
(43-407)\end{array}$ & $\begin{array}{c}144.64 \\
(40-473)\end{array}$ & 0.003 & $\begin{array}{c}172.43 \\
(23-504)\end{array}$ & $\begin{array}{c}150.05 \\
(27-473)\end{array}$ & 0.002 \\
\hline TAF & $\begin{array}{c}436.17 \\
(143-956)\end{array}$ & $\begin{array}{c}459.81 \\
(145-958)\end{array}$ & 0.622 & $\begin{array}{c}430.58 \\
(143-827)\end{array}$ & $\begin{array}{c}449.74 \\
(134-1032)\end{array}$ & 0.571 & $\begin{array}{c}432.84 \\
(113-1031)\end{array}$ & $\begin{array}{c}457.49 \\
(91-1032)\end{array}$ & 0.744 \\
\hline
\end{tabular}

VAT/SAT: ratio visceral to subcutaneous adipose tissue ratio. SAF: Subcutaneous Abdominal Fat, VAF: Visceral Abdominal Fat, TAF: Total Abdominal Fat.

Bonferroni correction was made multiplying by 4 comparisons $(P c)$. Significant $\mathrm{p}$ values are in bold.

ated with risk of developing $\mathrm{pCAD}$ or clinical/metabolic parameters. We found a higher frequency in the minor allele in the UCP2 -866 (rs659366) variants in the pCAD group, with a significant difference in the recessive model. Similar allele and genotype frequencies have been found in Asian populations (Oktavianthi et al., 2012). In spite that our study included an important number of patients and healthy controls, the statistical power for two polymorphisms was low [ $20 \%$ for UCP2 Ala55Val (C/T rs660339 and $6 \%$ for $U C P 3-55 C / T$ (rs1800849)]. Thus, the non significant results with these polymorphisms could be due to this lack of statistical power.

Other studies have explored the association of $U C P$ genes with abdominal obesity and lipid levels in several populations; yet, results have been inconclusive. In addition, most of the studies have been based on indices of ab- dominal obesity like waist circumference, waist-to-hip ratio (WHR) and body mass index. In our study, we ascertain the abdominal and visceral fat by computed tomography. Although no BMI difference between our groups was found, the analysis showed association between the UCP variants and SAF and VAF levels. These results indicate an increase in the VAF in pCAD subjects depending of the UCP2 55 (rs660339) TT, UCP2 -866 (rs659366) AA and UCP3 -55TT (rs1800849) genotypes. Some studies have reported that a high fat diet increases $U C P 2$ mRNA expression in white adipose tissue in some mouse strains (Surwit et al., 1998). In Caucasoid and Indian populations, the UCP 3 -55 (rs1800849) $T$ allele was associated with abdominal obesity (Cassel et al., 2000; Herrmann et al., 2003), meanwhile in Asian population the $C$ allele present in the CGTACC haplotype was associated with this condition 
Table 5 - Association of $U C P$ polymorphisms with cardiovascular risk factors.

\begin{tabular}{|c|c|c|c|c|c|c|c|c|c|c|}
\hline & \multirow[b]{2}{*}{ Model } & \multicolumn{3}{|c|}{$U C P 2 A 55 \mathrm{~V}$} & \multicolumn{3}{|c|}{$U C P 2-866$} & \multicolumn{3}{|c|}{$U C P 3-55 C / T$} \\
\hline & & $P c$ & OR & $95 \% \mathrm{CI}$ & $P c$ & OR & $95 \% \mathrm{CI}$ & $P c$ & OR & $95 \% \mathrm{CI}$ \\
\hline \multirow[t]{2}{*}{$\mathrm{BMI}>30 \mathrm{~kg} / \mathrm{cm}^{2}$} & Recessive & 0.003 & 1.64 & $1.30-2.06$ & 0.063 & 1.87 & $1.18-2.45$ & 0.540 & 2.50 & $\begin{array}{c}0.42-12.7 \\
6\end{array}$ \\
\hline & Additive & 0.001 & 1.44 & $1.15-1.80$ & 0.030 & 1.45 & $1.16-1.81$ & 0.197 & 1.60 & $0.88-2.09$ \\
\hline \multirow[t]{2}{*}{$\mathrm{HT}>140 \mathrm{mmHg}$} & Recessive & 0.069 & 1.84 & $0.99-3.42$ & 0.221 & 2.03 & $1.05-3.93$ & 0.007 & 6.53 & $5.16-8.27$ \\
\hline & Additive & 0.052 & 1.33 & $1.00-1.77$ & 0.049 & 1.72 & $1.23-2.41$ & 0.011 & 6.55 & $5.21-8.31$ \\
\hline \multirow[t]{2}{*}{ Hypercholesterolemia $>160 \mathrm{mg} / \mathrm{dL}$} & Recessive & 0.051 & 0.23 & $0.15-0.36$ & 0.006 & 3.41 & $2.22-5.26$ & 0.007 & 2.53 & $1.92-3.44$ \\
\hline & Additive & 0.062 & 0.22 & $0.18-0.28$ & 0.038 & 1.65 & $1.26-2.17$ & 0.011 & 2.56 & $1.95-3.49$ \\
\hline \multirow[t]{2}{*}{ LDL-C $>130 \mathrm{mg} / \mathrm{dL}$} & Recessive & 0.070 & 0.23 & $0.14-0.37$ & 0.096 & 1.96 & $1.22-3.16$ & 0.618 & 2.00 & $0.42-9.51$ \\
\hline & Additive & 0.015 & 3.01 & $2.40-3.78$ & 0.030 & 0.14 & $0.10-0.19$ & 0.236 & 3.03 & $1.94-4.63$ \\
\hline \multirow[t]{2}{*}{ Hypertriglyceridemia $>150 \mathrm{mg} / \mathrm{dL}$} & Recessive & 0.066 & 0.57 & $0.39-0.84$ & 0.151 & 2.63 & $1.76-3.92$ & 0.006 & 1.99 & $1.61-2.53$ \\
\hline & Additive & 0.059 & 0.53 & $0.44-0.65$ & 0.100 & 2.20 & $1.81-2.67$ & 0.010 & 2.01 & $1.69-2.62$ \\
\hline \multirow[t]{2}{*}{ Hypoalphalipoproteinemia $<40 \mathrm{mg} / \mathrm{dL}$} & Recessive & 0.168 & 1.56 & $1.07-2.26$ & 0.910 & 1.04 & $0.71-1.52$ & 0.862 & 1.37 & $0.38-4.86$ \\
\hline & Additive & 0.054 & 1.33 & $1.11-1.60$ & 0.296 & 0.90 & $0.75-1.08$ & 0.984 & 1.01 & $0.72-1.42$ \\
\hline \multirow[t]{2}{*}{$\mathrm{T} 2 \mathrm{DM}$} & Recessive & 0.086 & 2.08 & $1.22-3.52$ & 0.001 & 2.72 & $1.64-4.50$ & 0.007 & 2.26 & $1.70-3.01$ \\
\hline & Additive & 0.050 & 2.09 & $1.63-2.69$ & $<0.001$ & 2.85 & $1.74-4.65$ & 0.011 & 2.30 & $1.74-3.06$ \\
\hline
\end{tabular}

All associations were tested using logistic regression adjusting for age, gender, smoking habits and physical activity. BMI: body mass index, HT: hypertension; LDL-C: Low density lipoprotein-cholesterol; T2DM: Type 2 diabetes mellitus. Bonferroni correction was made multiplying by 7 comparisons $(\mathrm{Pc})$. Significant $\mathrm{p}$ values are in bold.

(Cha et al., 2007). Also, the UCP2 -866 (rs659366) $A$ allele was associated with lower abdominal obesity indices in Caucasian population (Salopuro et al., 2009). Despite the consistency of these findings with previous reports, contradictory results have been reported in different populations (Pedersen et al., 2005; Qin et al., 2013; Xu, et al., 2011). This could be due to diet and life style, genetic charge between different ethnic groups, and also to the sample size, source of controls and genotyping methods.

Previous studies have found that UCP2 A55V (rs660339) polymorphism is associated with cardiovascular event risk in patients with CAD and dysglycemia (Gioli-Pereira et al., 2013). Alternatively, other research groups have reported that subjects carrying the $\mathrm{Val} / \mathrm{Val}$ genotype in this polymorphism appear to have the following traits: a lower degree of uncoupling of the mitochondrial internal membrane, lower energy expenditure (Astrup et al., 1999), higher exercise energy efficiency (Buemann et al., 2001), higher metabolic rate, high atherogenic index, increased susceptibility to obesity and T2DM and greater weight loss than subjects with the Ala allele (De Souza et al., 2013; Brondani et al., 2014). In our study, the UCP2 $A 55 \mathrm{~V}$ (rs660339) polymorphism was associated with BMI $>30 \mathrm{Kg} / \mathrm{cm}^{2}$.

Also, Pedersen et al. (2005) reported that UCP2 and $U C P 3$ increase the serum lipid levels and abdominal obesity index, and so contribute to T2DM. Hence, different studies have described conflicting results: some studies found a negative association between $U C P$ genes and obesity, while others found a positive association or none at all (Astrup et al., 1999; Esterbauer et al., 2001; Xu et al., 2011;
Qin et al., 2013). The UCP2 -866GA (rs659366) polymorphism has been associated with prevalence of obesity (Pedersen et al., 2005), and decreased or increased risk of T2DM (Bulotta et al., 2005; Cheurfa et al., 2008). In our study, this polymorphism was associated with high BMI and increased risk of T2DM.

In a meta-analysis, Qin et al. (2013) documented that UCP2 A55V (rs660339) and UCP3 -55C/T (rs1800849) polymorphisms were associated with T2DM susceptibility in Asian populations, whereas UCP2 -866G/A (rs659366) was linked to obesity in the European, but not the Asian population. Further, the UCP2 -55T (rs660339) allele has been associated with greater energy expenditure, T2DM and cardiovascular risk, the UCP2 -866 A (rs659366) allele has been associated with obesity and increased cardiovascular risk and T2DM in obese individuals, meanwhile, the UCP3 T (rs1800849) allele was linked to BMI, and reduced energy expenditure (Buemann et al., 2001; Reis et al., 2004; Gable et al., 2006).

In the present study, the UCP2 and UCP3 variants were associated with an increase in visceral fat and an increased risk of pCAD. A possible explanation is that $U C P$ variants attenuate mRNA levels which leads to a diminished fat oxidation, consequently, this augments the risk of pCAD. Further investigation is merited to assess the mRNA levels and the oxidation patients with $\mathrm{pCAD}$ in the context of $U C P 2$ and $U C P 3$ variants.

Many studies have established that the effect of the genetic polymorphisms on UCP2 and UCP3 vary depending on physical activity and lifestyle (Berentzen et al., 2005; Holdys et al., 2013; Gronek et al., 2013). Specifi- 
cally, in the present study, the analyses were adjusted for confounders, such as gender, age, smoking habit, and physical activity.

In conclusion, our study revealed there is a direct relationship between visceral and abdominal fat accumulation depending on $U C P$ polymorphisms, which seem to be related to BMI, high levels of cholesterol, triglycerides and $\mathrm{T} 2 \mathrm{DM}$ in $\mathrm{pCAD}$ patients.

\section{References}

Argiles JM, Busquets S and Lopez-Soriano FJ (2002) The role of uncoupling proteins in pathophysiological states. Biochem Biophys Res Commun 293:1145-1152.

Astrup A, Toubro S, Dalgaard LT, Urhammer SA, Sorensen TI and Pedersen O (1999) Impact of the V/V 55 polymorphism of the uncoupling protein 2 gene on 24-h energy expenditure and substrate oxidation. Int $\mathrm{J}$ Obes Relat Metab Disord 23:1030-1034.

Berentzen T, Dalgaard LT, Petersen O and Sorensen TI (2005) Interaction between physical activity and variants of the genes encoding uncoupling proteins -2 and -3 in relation to body weight changes during a 10-y follow-up. J Obes 29:93-99.

Blanc J, Alves-Guerra MC, Esposito B, Rousset S, Gourdy P, Ricquier D, Tedqui A, Miroux B and Mallat Z (2003) Protective role of uncoupling protein 2 in atherosclerosis. Circulation 107:388-390.

Boss O, Samec S, Dulloo A, Seydoux J, Muzzin P and Giacobino JP (1997) Tissue-dependent upregulation of rat uncoupling protein-2 expression in response to fasting or cold. FEBS Lett 412:111-114.

Brondani LA, Assmann TS, Duarte GCK, Gross JL, Canani LH and Crispim D (2012) The role of the uncoupling protein 1 (UCP1) on the development of obesity and type 2 diabetes mellitus. Arq Bras Endocrinol Metabol 56: 215-225.

Brondani LA, Assmann TS, de Souza BM, Bouas AP, Canani LH and Crispim D (2014) Meta-analysis reveals the association of common variants in the uncoupling protein (UCP) 1-3 genes with body mass index variability. PLoS One 9:e96411.

Buemann B, Schierning B, Toubro S, Bibby BM, SØrensen T, Dalgaard L, Pedersen O and Astrup A (2001) The association between the val/ala- 55 polymorphism of the uncoupling protein 2 gene and exercise efficiency. Int $\mathrm{J}$ Obes Relat Metab Disord 25:467-471.

Bulotta A, Ludovico O, Coco A, Di Paola R, Quattrone A, Carella M, Pellegrini F, Prudente S, and Trischitta V (2005) The common $-866 \mathrm{G}>\mathrm{A}$ variant in the promoter region of the UCP2 gene is associated with risk of type 2 diabetes in Caucasians from Italy. J Endocinol Metab 90:1176-1180.

Cassel PG, Saker PJ, Huxtable SJ, Kosuta E, Jackson AE, Hattersley AT, Frayling TM, Walker M, Kopelman M, Ramachamdran A, et al. (2000) Evidence that the single nucleotide polymorphism in the uncoupling protein 3 (UCP3) gene influences fat distribution in women European and Asian origin. Diabetologia 43:1558-1564.

Center for Disease Control and Prevention (2010) Prevalence of abnormal lipid levels among youth. United States, 19992006. MMWR Morb Mortal Wkly Rep 59:78.

Cha MH, Kim IC, Kim KS, Kang BK, Choi SM and Yoon Y (2007) Association UCP2 and UCP3 gene polymorphisms with serum high density lipoprotein cholesterol among Korean women. Metabolism 56:806-813.

Cheurfa N, Dubois-Laforgue D, Ferrarezi DA, Reis AF, Brenner GM, Bouche C, Le Fauvre C, Fumeron F, Timsit J, Marre M, et al. (2008) The common $-866 \mathrm{G}>\mathrm{A}$ variant in the promoter of UCP2 is associated with decreased risk of coronary artery disease in type 2 diabetic men. Diabetes 57:1063-1068.

De Souza BM, Assmann TS, Kliemann LM, Gross JL, Canani LH and Crispim D (2011) The role of uncoupling protein 2 (UCP2) on the development of type 2 diabetes mellitus and its chronic complications. Arq Bras Endocrinol Metabol 55:239-248

De Souza BM, Brondani LA, Bouas AP, Sortica DA, Kramer CK, Canani LH, Leitao CB, and Crispim D (2013) Associations between UCP1 -3826A/G, UCP2 -866G/A, Ala55Val and Ins/Del and UCP3 -55C/T polymorphisms and susceptibility to type 2 diabetes mellitus: case-control study and meta-analysis. PLoS One 8:e54259.

De Long DM, De Long ER, Wood PD, Lippel K and Rifkind BM (1986) A comparison of methods for the estimation of plasma low- and very low-density lipoprotein cholesterol. The Lipid Research Clinics Prevalence Study. JAMA 256:2372-2377.

Dhamrait SS, Stephens JW, Cooper JA, Acharya J, Mani AR, Moore K, Miller GJ, Humphries SE, Hurel SJ and Montgomery HE (2004) Cardiovascular risk in healthy men and markers of oxidative stress in diabetic men are associated with common variation in the gene for uncoupling protein 2 . Eur Heart J 25:468-475.

Esterbauer H, Schneitler C, Oberkofler H, Ebenbichler C, Pualweber B, Sandhofer F, Ladurner G, Hell E, Strosberg AD, Patsch JR, et al. (2001) A common polymorphism in the promoter In UCP2 is associated with deceased risk of obesity in middle age humans. Nat Genet 28:178-183.

Fleury C, Neverova M, Collins S, Raimbault S, Champigny O, Levi-Meyrueis C, Bouillaud F, Seldin MF, Sirwit RS, Ricquier RS, et al. (1997) Uncoupling protein-2: a novel gene linked to obesity and hyperinsulinemia. Nat Genet 15:269272.

Gable DR, Stephens JW, Cooper JA, Miller GJ, and Humphries SE (2006) Variation in the UCP2-UCP3 gene cluster predicts the development of type 2 diabetes in healthy middle age men. Diabetes 55:1504-1511.

Gioli-Pereira L, Santos PC, Sugaya LS, Ferreira NE, Krieger JE, Pereira AC and Hueb WA (2013) Association between UCP2 A55V polymorphism and risk of cardiovascular events in patients with multi-vessel coronary arterial disease. BMC Med Genet 14:40.

Gronek P and Holdys J (2013) Genes and physical fitness. Trends Sport Sci 20:16-29.

Herrmann SM, Wang JG, Staessen JA, Kertmenn E, SchmidtPetersen K, Zidek W, Paul M and Brand E (2003) Uncoupling protein 1 and 3 polymorphisms are associated with waist to hip ratio. J Mol Med 81:327-332.

Holdys J, Gronek P, Krysciak J, and Stanislawski D (2013) Genetic variants of uncoupling proteins- 2 and- 3 in relation to maximal oxygen uptake in different sports. Acta Biochim Pol 60:71-75.

Jia JJ, Zhang X, Ge CR and Jois M (2009) The polymorphisms of UCP2 and UCP3 genes associated with fat metabolism, obesity and diabetes. Obes Rev 10:519-526. 
Jia JJ, Tian YB, Cao ZH, Tao LL, Zhang X, Gao SZ, Ge CR, Lin QY and Jois M (2010) The polymorphisms of UCP1 genes associated with fat metabolism, obesity and diabetes. Mol Biol Rep 37:1513-1522.

Kil SK, Dae-Yeon C, Young JK, Sun MC, Jong YK, Seung US and Yoo SK (2005) The finding of new genetic polymorphism of UCP-1 A-1766G and its effects on body fat accumulation. Biochim Biophys Acta 1741:149-155.

Kvist H, Chowdhury B, Grangrd U, Tylén U and Sjstrm L (1988) Total and visceral adipose-tissue volumes derived from measurements with computed tomography in adult men and women: predictive equations. Am J Clin Nutr 48:13511361.

Ledesma A, Garcia de Lacoba M and Rial E (2002) Protein family review. The mitochondrial uncoupling proteins. Genome Biol 3015:1-9.

Longo R, Ricci C, Masutti F, Vidimari R, Crocé LS, Bercich L, Tiribelli C and Dalla PL (1993) Fatty infiltration of the liver. Quantification by IH localized magnetic resonance spectroscopy and comparison with computed tomography. Invest Radiol 28:297-302.

Makedou KG, Mikhaidilis DP, Makedou A, Illiadis S, Kourtis A, Vavatsi-Christaki N and Papageorgiou GE (2009) Lipid profile, low density lipoprotein oxidation and ceruloplasmin in the progeny of families with positive history of cardiovascular diseases and/or hyperlipidemia. Angiology 4:455-461.

Mautner GC, Mautner SL, Froehlich J, Feuerstein IM, Proschan MA, Roberts WC and Doppman JL. (1994) Coronary artery calcification: assessment with electron beam CT and histomorphometric correlation. Radiology 192:619-623.

McLeod CJ, Aziz A, Hoyt Jr RF, McCoy Jr JP and Sack MN (2005) Uncoupling proteins 2 and 3 function in concert to augment tolerance to cardiac ischemia. J Biol Chem 280:33470-33476.

Muzzio F, Mondazzi U, Sommariva D and Branchi A (2005) Long term effects of low calorie diet on the metabolic syndrome in obese nondiabetic patients. Diabetes Care 28:1485-1486.

Norhammar A, Tenerz A, Nilsson G, Hamsten A, Efendic S, Ryden L and Malmberg K (2002) Glucose metabolism in patients with acute myocardial infarction and no previous diagnosis of diabetes mellitus: a prospective study. Lancet 359:2140-2144.

Oberkofler H, Iglseder B, Klein K, Unger J, Haltmayer M, Krempler F, Paulweber B and Patsch W (2005) Associations of the UCP2 gene locus with asymptomatic carotid atherosclerosis in middle-aged women. Arterioscler Thromb Vasc Biol 25:604-610.

Oktavianthi S, Trimarsanto H, Febinia CA, Saustika MR, Saraswati MR, Dwipayana P, Arindrarto W, Sudoyo H and Malik SG (2012) Uncoupling protein 2 polymorphisms are associated with obesity. Cardiovasc Diabetol 11:41.

Pedersen SB, Nyholm B, Kristensen K, Nielsen MF, Schmitz O and Richelsen B (2005) Increased adiposity and reduced ad- ipose tissue mRNA expression of uncoupling protein-2 in first-degree relatives of type 2 diabetic patients: evidence for insulin stimulation of UCP-2 and UCP-3 gene expression in adipose tissue. Diabetes Obes Metab 7:98-105.

Pischon T (2009) Use of biomarkers in cardiovascular epidemiology. Dis Markers 26:247-263.

Qin LJ, Wen J, Qu YL and Huang QY (2013) Lack of association of functional UCP2 -866G/A and Ala55Val polymorphisms and type 2 diabetes in the Chinese population based on a case-control study and a meta-analysis. Genet Mol Res 12:3324-3334.

Reis AF, Dubois-Laforgue D, Bellane-Chantelot C, Timsit J and Vehlo G (2004) A polymorphisms in the promoter UCP2 gene modulates lipid levels in patients with diabetes mellitus type 2. Mol Genet Metab 82:339-344.

Salopuro T, Pulkkinen L, Lindstrm J, Kolehmainen M, Tolppanen AM, Eriksson JG, Valle TT, Aunola S, llane-Parikka S, Keinanen-Kiukaanniemi S, et al. (2009) Variation in the UCP2 and UCP3 genes associates with abdominal obesity and serum lipids: the Finnish Diabetes Prevention Study. BMC Med Genet 10:94.

Schrauwen P and Hesselink M (2002) UCP2 and UCP3 in muscle controlling body metabolism. J Exp Biol 205:2275-2285.

Surwit RS, Wang S, Petro AE, Sanchis D, Raimbault S, Ricquier $D$ and Collins S (1998) Diet-induced changes in uncoupling proteins in obesity-prone and obesity-resistant strains of mice. Proc Natl Acad Sci U S A 95:4061-4065.

Teshima Y, Akao M, Jones SP and Marban E (2003) Uncoupling protein-2 overexpression inhibits mitochondrial death pathway in cardiomyocytes. Circ Res 93:192D200.

Vasan RS (2003) Cardiac function and obesity. Heart 89:11271129.

Villarreal-Molina T, Posadas-Romero C, Romero-Hidalgo S, Antnez-Arguelles E, Bautista-Grande A, Vargas-Alarcón G, Kimura-Hamaya E, Canizales-Quinteros S, Juarez-Rojas JG, Posadas-Sánchez R, et al. (2012) The ABCA1 gene $\mathrm{R} 230 \mathrm{C}$ variant is associated with decreased risk of premature coronary artery disease: The genetics of atherosclerosis disease (GEA) study. Plos One 7:e49285.

Xu K, Zhang M, Cui D, Fu Y, Qian L, Gu R, Wang M, Shen C, Yu $\mathrm{R}$ and Yang T (2011) UCP2 -866G/A and Ala55Val, and UCP3 -55C/T polymorphisms in association with type 2 diabetes susceptibility: a meta-analysis study. Diabetologia 54:2315-2324.

Zamboni M, Mazzali G, Zoico E, Harris TB, Meigs JB, Di FV, Fantin F, Bissoli L and Bosello O (2005) Health consequences obesity in the elderly: A review of four unresolved questions. Int J Obes 29:1011-1029.

Associate Editor: Maria Angélica Cortez

License information: This is an open-access article distributed under the terms of the Creative Commons Attribution License (type CC-BY), which permits unrestricted use, distribution and reproduction in any medium, provided the original article is properly cited. 